\title{
EFFECT OF OPERATING TEMPERATURE ON PHYSIOCHEMICAL PROPERTIES OF EMPTY FRUIT BUNCH CELLULOSE-DERIVED BIOCHAR
}

\author{
STASHA ELEANOR ROSLAND ABEL*,;; SOH KHEANG LOH*; NOORSHAMSIANA ABDUL WAHAB*; \\ ONDREJ MASEK ${ }^{\star *}$; MUSA IDRIS TANIMU ${ }^{\ddagger}$ and ROBERT THOMAS BACHMANN ${ }^{\ddagger}$
}

\begin{abstract}
The oil palm lignocellulosic biomass is mass-produced which leads to management and disposal issue. Hence, converting it into carbonaceous material such as biochar is advantageous. One such by-products namely empty fruit bunch (EFB), comprises of 44.4 wt\% cellulose, rendering it a prominent feedstock for biochar production. The study focuses on assessing the effect of pyrolysis temperatures on cellulose biochar properties and yields. The cellulose was extracted via standard method and carbonised using thermogravimetric analyser. The proximate and ultimate analyses and Fourier-transform infrared spectroscopy (FTIR) were performed to determine the biochar characteristics. Lower biochar yield, volatile matter (VM) and hydrogen contents were generated at higher temperature, whereas an opposite trend was observed for moisture, fixed carbon and ash contents. The FTIR spectra verified the presence of carboxyl, aromatic and hydroxyl groups at $250^{\circ} \mathrm{C}$ and $400^{\circ} \mathrm{C}$; however, the bands diminished at $750^{\circ} \mathrm{C}$. This work has identified that biochar produced at $250^{\circ} \mathrm{C}$ possesses excellent properties including higher biochar yield $(32.51 \% \pm 0.48)$, carbon content (57.98 $w t \%)$ and VM (38.68 wt\%). High level of VM is beneficial for microbial rejuvenation, which is ideal for soil amendment. This study provides a key basis in establishing the suitable biochar properties and pyrolysis parameter for soil amendment as well as other applications.
\end{abstract}

Keywords: biochar, cellulose, empty fruit bunch, pyrolysis, thermal degradation.

Received: 15 September 2020; Accepted: 1 December 2020; Published online: 23 February 2021.

\section{INTRODUCTION}

Nowadays, heavy dependency on non-renewable fuels such as petroleum as main energy source has resulted in a severe energy calamity and degradation of the environment. As such, there has been a shift of interest in utilising biomass waste as a fossil fuel

\footnotetext{
* Malaysian Palm Oil Board,

6 Persiaran Institusi, Bandar Baru Bangi,

43000 Kajang, Selangor, Malaysia.

E-mail: stasha.eleanor@mpob.gov.my

** UK Biochar Research Centre, School of Geosciences, University of Edinburgh, Edinburgh, EH9 3FF,

United Kingdom.

₹ Section of Environmental and Polymer Engineering Technology, Universiti Kuala Lumpur MICET, Lot 1988, Taboh Naning, 78000 Alor Gajah, Melaka, Malaysia.
}

substitute, as it emits less greenhouse gas (GHG) when combusted due to its carbon-rich characteristics comprising of cellulose, hemicellulose and lignin and thus, greatly reduces reliance on fossil fuel.

With contribution of $47 \%$ to the world's palm oil supply, Malaysia is the second largest country to produce and export palm oil (Kushairi et al., 2019). Processing of $1 \mathrm{t}$ fresh fruit bunches (FFB) generates 20\%-22\% crude palm oil (CPO) along with other oil palm biomass by-products including 23\%-25\% empty fruit bunches (EFB), 13\%-15\% mesocarp fibre (MF) and 5\%-6\% palm kernel shell (PKS). In palm oil mills, EFB is normally utilised as fuel in boilers for steam and electricity generation or incinerated for fertiliser production. However, a vast amount is still available and unutilised, hence means of disposing them cost-effectively is important (Lahijani and Zainal, 2011). Disposal of oil palm biomass solid 
by-products, i.e. EFB poses challenges since they are poorly utilised which might cause several issues for instance inadequate disposal areas, unpleasant odour and gas emitted due to biomass degradation (Novianti et al., 2014). In comparison to incineration and other disposal methods, EFB can be pyrolysed and converted into a valuable product such as biochar. This provides an opportunity to utilise them cost-effectively for many different applications including soil fertility enhancement. EFB is a lignocellulosic biomass comprising of $44.4 \%$ cellulose fraction and 14\%-31\% lignin, in total $\sim 60 \%$, rendering it a great feedstock for the production of bioenergy. Among these biomass components in EFB, cellulose is frequently used to represent lignocellulosic biomass because it is a primary structural component, which makes up 40$60 \mathrm{wt} \%$ besides hemicellulose and lignin (Heinze et al., 2018). This cellulosic material offers enormous potential to be employed as a renewable feedstock, i.e. for biochar production due to abundant availability and low-cost.

Biochar can be used as an alternative to pure charcoal which possesses some negative impacts to the environment including GHG emissions, ozone depletion and ultimately, changing the world climate. According to Sohi et al. (2009), biochar is a stable solid form of carbon, which is capable of reducing GHG emissions and performing carbon dioxide sequestration at billion-tonne scale within 30 years. Besides, biochar can exert beneficial properties on soils such as increased cation exchange capacity (CEC), soil $\mathrm{pH}$ and moisture (Shafie et al. 2012), phosphorus ions and total nitrogen, promotes development of root (Chan et al. (2008), diminishes soil erosion and nutrient leaching in drought season (Lorenz, 2007). In 2015, Domene et al. conducted a 28-day soil incubation experiment by using biochar produced at different temperatures and observed that biochar-amended soil basal respiration was significantly stimulated but decreased with increasing pyrolysis temperature and increased with a higher volatile matter (VM) content. These findings suggest that a labile carbon pool exists in the biochar that is biodegradable under aerobic conditions and correlated to the VM content. The labile carbon pool is the fraction of total soil organic carbon (SOC) with the most rapid turnover rates and consists of living microbes besides soil organic matter. It fuels the soil food web and therefore greatly influences nutrient cycling for maintaining soil quality and its productivity.

Generally, the quality and biochar yield are critically impacted by several factors, namely pyrolysis temperature, biomass type, process heating rate, residence time and others. Of these, pyrolysis temperature is the most influential showing notable modification on the physical and chemical characteristics of biochar. Many studies have been reported on converting lignocellulosic biomass, i.e., raw EFB into biochar (Aziz et al., 2015; Idris et al., 2014) but limited reports on utilising individual biomass component such as cellulose, lignin and hemicelluloses. Cellulose is the most dominant material in EFB and exhibits immense potential as a renewable feedstock, i.e. for biochar production attributable to inexpensive cost and abundant availability. Hence, the study on cellulose pyrolysis would be particularly beneficial for achieving better understanding of the biomass pyrolytic mechanism and facilitating its direct application in terms of bio-materials, chemicals, etc. To our knowledge, no recent study has utilised cellulose derived from EFB as a feedstock material to produce biochar. Hence, this study focuses to extract cellulose from raw EFB fibre and to perform pyrolysis experiments on EFBC at varied temperatures $\left(250^{\circ} \mathrm{C}, 400^{\circ} \mathrm{C}\right.$ and $\left.750^{\circ} \mathrm{C}\right)$ to evaluate the influence of operating temperature on EFBCderived biochar properties. Besides, the biochars produced will be characterised to identify which biochar exhibits higher VM content contributing to higher labile carbon pool which is beneficial as a soil amendment to improve soil quality.

\section{MATERIALS AND METHODS}

\section{Materials}

Raw EFB fibres were sourced from a palm oil mill located at Kota Tinggi, Johor, Malaysia. All chemicals used were of analytical grade purchased from Merck, Germany. Commercial microcrystalline cellulose (Sigma Corporation, USA) was used as a control sample.

\section{Method}

Sample preparation. The EFB was washed with distilled water to eliminate contaminant prior to drying in an oven for $24 \mathrm{hr}$ at temperature of $105^{\circ} \mathrm{C}$. The dried EFB was then cut into small pieces and ground using fibre grinders (Retsch, model AS200, USA) and screened to a range of particle sizes between 180-250 $\mu \mathrm{m}$.

Cellulose extraction. Extraction of cellulose from EFB was carried out according to ASTM standard method D1103-60. About $12 \mathrm{~g}$ of EFB was placed in a 1-litre beaker containing $480 \mathrm{ml}$ distilled water, $1.5 \mathrm{ml}$ acetic acid and $4.5 \mathrm{~g}$ sodium chlorite. The mixture was stirred on a hot plate with temperature set at $75^{\circ} \mathrm{C}$. Acetic acid, $1.5 \mathrm{ml}$ and $4.5 \mathrm{~g}$ sodium chlorite were added into the reaction mixture after $1 \mathrm{hr}$ and the same amount repeated after $2 \mathrm{hr}$. The volume of water was maintained during the chlorination duration. After cooling the reaction 
mixture to $<10^{\circ} \mathrm{C}$, the slurry was filtered using a $50-\mu \mathrm{m}$ sieve filter for liquid and solid separation. The solid was then put in the petri dish and dried overnight to obtain holocellulose. Approximately 2 $\mathrm{g}$ of holocellulose was poured into a glass beaker together with $20 \mathrm{ml}$ of cold sodium hydroxide $(\mathrm{NaOH}) \quad(17.5 \% \quad \mathrm{w} / \mathrm{v})$ solution and stirred continuously for $5 \mathrm{~min}$. Another $10 \mathrm{ml}$ of $\mathrm{NaOH}$ $(17.5 \% \mathrm{w} / \mathrm{v})$ solution was added after 5 and $10 \mathrm{~min}$ repetitively and the mixture was allowed to stand for $30 \mathrm{~min}$ at $20^{\circ} \mathrm{C}$. Then, $67 \mathrm{ml} 20^{\circ} \mathrm{C}$ cold distilled water was put in the mixture and stirred thoroughly for $45 \mathrm{~min}$ with temperature maintained at $20^{\circ} \mathrm{C}$ before filtering. The $\alpha$-cellulose extracted was washed with $50 \mathrm{ml}$ of cold $\mathrm{NaOH}(8.3 \% \mathrm{w} / \mathrm{v})$ twice and distilled water. Lastly, the $\alpha$-cellulose was immersed in $25 \mathrm{ml}$ acetic acid (10\% v/v) and rinsed with distilled water prior to oven-drying at $105^{\circ} \mathrm{C}$ overnight to obtain a constant weight.

Biochar production. The experiment of biochar production was established by carbonising the EFBC via a thermogravimetric analyser (TGA 701 LECO, USA) at three different thermo-chemical conditions: $250^{\circ} \mathrm{C}, 400^{\circ} \mathrm{C}$ and $750^{\circ} \mathrm{C}$. The EFBC was placed into a ceramic cubicle and heated from $30^{\circ} \mathrm{C}-105^{\circ} \mathrm{C}$ at

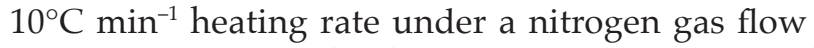

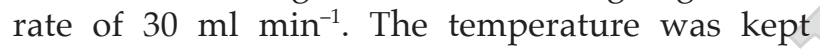
constant for $10 \mathrm{~min}$ at $105^{\circ} \mathrm{C}$ and then increased to the defined temperatures. The biochar produced at varied temperatures of $250^{\circ} \mathrm{C}, 400^{\circ} \mathrm{C}$ and $750^{\circ} \mathrm{C}$ were collected for further analysis.

Characterisation. The raw EFB fibre, commercial cellulose, EFBC and EFBC-derived biochar were characterised as follows:

\section{i) Fourier-transform Infrared Spectroscopy (FTIR)}

The chemical bond and functional groups of the samples were elucidated using FTIR (Perkin-Elmer Frontier, USA) at $4 \mathrm{~cm}^{-1}$ resolution and eight scans. Potassium bromide was mixed with the oven-dried samples and then pressed using a mortar to form a disk. Spectra of the analysed samples were recorded over a wavelength from $4000 \mathrm{~cm}^{-1}$ to $650 \mathrm{~cm}^{-1}$.

\section{ii) Morphology Analysis}

The surface morphology and elemental analysis of the samples were conducted via scanning electron microscopy (SEM) (Hitachi Model S-3400N, Japan) at $30 \mathrm{kV}$ accelerating voltage. The sample surfaces were placed on the aluminum stubs and sputter-coated thinly by palladium to prevent electrostatic charging during analysis.

\section{iii) Proximate and Ultimate Analyses}

The proximate analysis of the samples was employed to determine the fixed carbon, moisture, VM and ash content via a thermogravimetric analyser (Perkin Elmer TGA-Pyris 6, USA) in accordance with the standard method American Society for Testing and Materials (ASTM) D1103-60, USA (Mayoral et al., 2001). The ultimate analysis for chemical compositions of the samples was determined using a CHNS Determinator (LECO CHNS M628, USA) according to ASTM D5373.

\section{RESULTS AND DISCUSSION}

\section{FTIR Analysis}

The effects of different temperatures on raw EFB fibre, commercial cellulose, EFBC and EFBCderived biochars functional groups were evaluated via FTIR spectroscopy. The FTIR spectra (Figure 1) showed two main regions i.e. fingerprint region (1450 to $400 \mathrm{~cm}^{-1}$ ) and functional group region (4000$1450 \mathrm{~cm}^{-1}$ ) (Lani et al., 2014). The absorption peaks at $3406 \mathrm{~cm}^{-1}$ are assigned to polymeric hydroxide $(-\mathrm{OH})$ intramolecular stretching, whereas those of 2850 $\mathrm{cm}^{-1}$ are attributed to methylene $\left(\mathrm{CH}_{2}\right)$ asymmetric stretching vibration (Khalil et al., 2001; Lv et al., 2015). As depicted in Figure 1, the peaks at 3406 $\mathrm{cm}^{-1}$ found in all spectra correspond to the stretching of hydrogen-bonded hydroxyl groups, indicating the presence of phenols and alcohols (Cantrell et al., 2012). However, the absence of vibration peak between $1750 \mathrm{~cm}^{-1}$ attributable to a waxy $\mathrm{C}=\mathrm{O}$ acetyl group (hemicellulose) and ester carbonyl groups (p-coumaric lignin) in all the feedstocks except for raw EFB fibre was indicative of successful removal of hemicelluloses and lignin components during EFBC extraction. Although the extracted cellulose was quite pure, there was residual lignin remained as indicated by absorption peak at $~ 1630$ $\mathrm{cm}^{-1}$ (Table 1). These findings also complement those of SEM results, showing smoother and wrinkled surface of EFBC thus, confirming that lignin and hemicellulose components have been completely removed. Besides, absorption peaks at around $3300 \mathrm{~cm}^{-1}, 2890 \mathrm{~cm}^{-1}, 1638 \mathrm{~cm}^{-1}, 1426 \mathrm{~cm}^{-1}, 1365$ $\mathrm{cm}^{-1}, 1310 \mathrm{~cm}^{-1}, 1210 \mathrm{~cm}^{-1}, 1028 \mathrm{~cm}^{-1}$ and $895 \mathrm{~cm}^{-1}$ were observed in both the commercial cellulose and EFBC, which indicated typical absorption characteristics for cellulose (Figures $1 b$ and 1c) ( $\mathrm{Lv}$ et al., 2015). The peaks at $1400 \mathrm{~cm}^{-1}, 760-800 \mathrm{~cm}^{-1}$ and $710 \mathrm{~cm}^{-1}$ (Figures $1 e$ and $1 f$ ) appearing in the EFBCderived biochars at higher temperature imply that some aromatic carbon structures are present due to condensation and aromatisation of biochar from decomposed cellulose. 
Based on the findings (Table 1), the bonds of $\equiv \mathrm{C}-\mathrm{H}$ bending $\left(1424 \mathrm{~cm}^{-1}\right)$ and $\mathrm{CH}_{2}$ wagging in cellulose $\left(1315 \mathrm{~cm}^{-1}\right)$ started to diminish when the temperature escalated from $250^{\circ} \mathrm{C}-750^{\circ} \mathrm{C}$, suggesting depolymerisation and degradation of cellulose. Similar pattern was observed for peaks appearing around $1214 \mathrm{~cm}^{-1}$ attributable to phenolic and ester C-O (hemicellulose) stretching. Meanwhile, the band within the saturated region of 2893-2852 $\mathrm{cm}^{-1}$ visible earlier in the raw EFB fibre (Figure 1a), commercial cellulose (Figure 1b), EFBC (Figure 1c) and EFBC-derived biochar at $250^{\circ} \mathrm{C}$ (Figure 1d) had slowly diminished (Figures $1 e$ and 1f) with increasing pyrolysis temperature. High loss of mass throughout the thermal decomposition could be the reason. According to Claoston et al. (2014), decomposition in the biomass accelerates a decline in the polar functional groups when pyrolysis temperature increases. Overall, the FTIR spectra demonstrated that EFBC was successfully extracted from the raw EFB fibre, as confirmed by similar functional groups exhibited between EFBC and commercial cellulose (Figures $1 b$ and $1 c$ ). Besides, the pyrolysis temperature employed was able to affect the existence of functional groups in the feedstock, where disappearance of functional groups became more distinct in the EFBC-derived biochars at higher pyrolysis temperature (Figures 1e and $1 f)$.

\section{Morphology Analysis}

Figure 2 depicts the physical appearance of feedstocks (raw EFB fibre and EFBC) and EFBC-derived biochar produced at different temperatures. It showed that EFBC had been completely carbonised, turning from yellowish to black at temperatures of $250^{\circ} \mathrm{C}, 400^{\circ} \mathrm{C}$ and $750^{\circ} \mathrm{C}$ (Figure 2d-f). The employed temperature ranges had successfully removed the surface and bound water resulted in great reduction of moisture content which then facilitated carbonisation of EFBC. These findings were consistent with a study previously reported by Uemura et al. (2011a). The morphological structures of raw EFB fibre, commercial cellulose, EFBC and EFBC-derived biochar were assessed via SEM at different magnification. These micrographs show gradual changes of the effect of different temperature on the surface textures. The SEM micrograph of raw EFB fibre in Figure $3 a$ indicated a lignocellulosic composite with compact fibrillar packing and the external surface suggested an irregular heavy deposition of wax, hemicelluloses and lignin. On the other hand, the commercial cellulose and EFBC (Figures $3 b$ and 3c) exhibited an isolated fibril which was separated from each other suggesting non-cellulosic components and impurities such as cuticle. The wax layer was removed from fibre surface during the extraction process which contributed to a more wrinkled and clearer surface (Draman et al., 2013; Nazir et al., 2013; Suriya et al., 2017). As illustrated in Figure $3 d$, the surface of biochar produced at $250^{\circ} \mathrm{C}$ appeared to be smoother with rough texture unlike those biochars generated at higher temperature $\left(400^{\circ} \mathrm{C}\right.$ and $\left.750^{\circ}\right)$, the external surface seemed to have been cracked with greater shrinkages. When temperature increased to $750^{\circ} \mathrm{C}$ (Figure 3f), the outer surface of the biochar produced began to collapse and fracture. Claoston et al. (2014) also reported similar findings as evidenced by the inability of the produced biochar to endure high temperature as the thin wall structure was fragile and easily diminished.

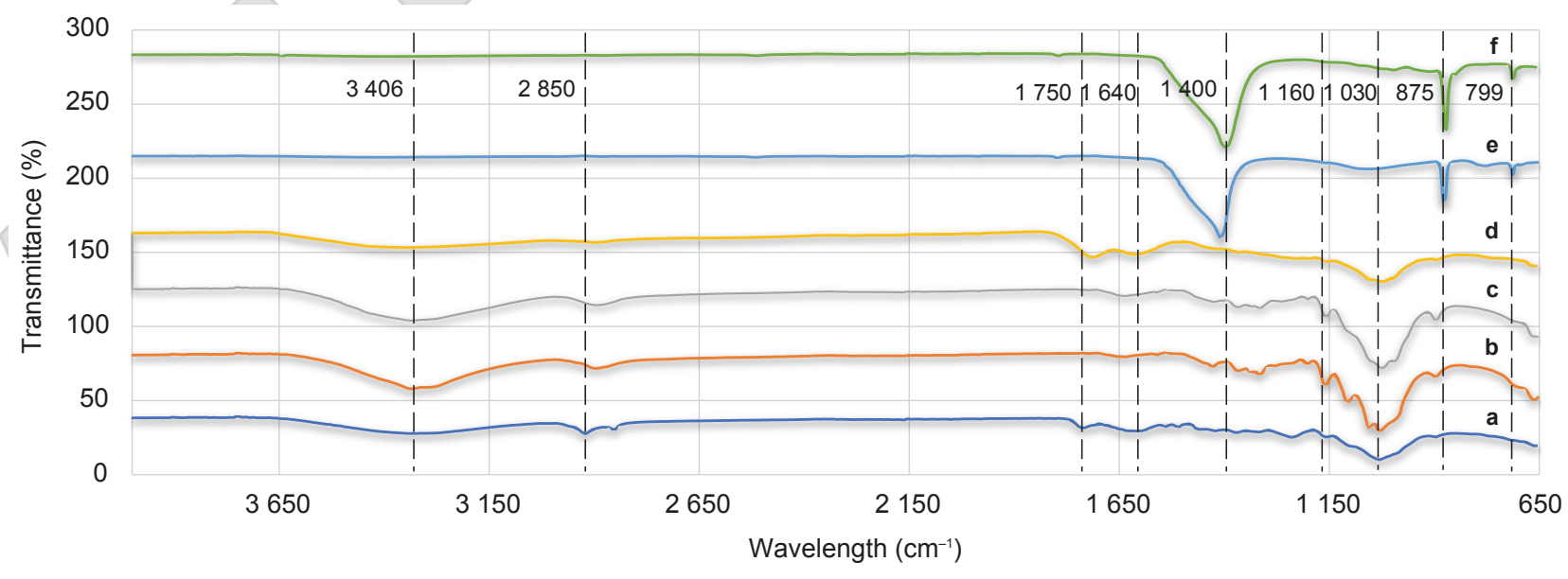

Figure 1. Fourier-transform infrared spectroscopy (FTIR) of (a) raw empty fruit bunch fibre, (b) commercial cellulose, (c) empty fruit bunch cellulose; empty fruit bunch cellulose-derived biochar produced at, $\left.(d) 250{ }^{\circ} \mathrm{C}, e\right) 400^{\circ} \mathrm{C}$, and $(f) 750^{\circ} \mathrm{C}$. The peaks for wax, hemicellulose and lignin exhibited by raw empty fruit bunch fibre were found absent in both the extracted and commercial cellulose showing evidence of non-cellulosic components loss. The bands of carboxyl, aromatic and other aromatic groups were clearly developed at $250^{\circ} \mathrm{C}$ but diminished as the temperature further increased. 
TABLE 1. FUNCTIONAL GROUPS OBSERVED IN THE FTIR SPECTRA OF RAW EMPTY FRUIT BUNCH (EFB) FIBRE, COMMERCIAL CELLULOSE, EFB CELLULOSE (EFBC) AND EFBC-DERIVED BIOCHARS PRODUCED AT DIFFERENT TEMPERATURES

\begin{tabular}{|c|c|c|c|c|c|c|c|c|}
\hline \multirow{2}{*}{$\begin{array}{l}\text { Wavenumbers } \\
\qquad\left(\mathrm{cm}^{-1}\right)\end{array}$} & \multirow{2}{*}{$\begin{array}{l}\text { Functional groups } \\
\text { and bonds }\end{array}$} & \multirow{2}{*}{$\begin{array}{l}\text { Raw EFB } \\
\text { fibre }\end{array}$} & \multirow{2}{*}{$\begin{array}{l}\text { Commercial } \\
\text { cellulose }\end{array}$} & \multirow[t]{2}{*}{ EFBC } & \multicolumn{3}{|c|}{ EFBC-derived biochars } & \multirow[t]{2}{*}{ References } \\
\hline & & & & & $250^{\circ} \mathrm{C}$ & $400^{\circ} \mathrm{C}$ & $750^{\circ} \mathrm{C}$ & \\
\hline 3406 & $\begin{array}{c}\text { Polymeric -OH } \\
\text { intramolecular stretching } \\
\text { (cellulose) }\end{array}$ & $3333(\mathrm{~s})$ & $3333(\mathrm{~s})$ & $3334(s)$ & $3346(\mathrm{~m})$ & $3410(w)$ & $3414(w)$ & $\begin{array}{l}\text { Lv et al. (2015); } \\
\text { Wan et al. (2011) }\end{array}$ \\
\hline 2850 & $\begin{array}{l}\text { S-H stretching, } \mathrm{O}=\mathrm{C}-\mathrm{H} \text {, } \\
\mathrm{CH}_{2} \text { asymmetric } \\
\text { stretching }\end{array}$ & $2852(w)$ & $2896(\mathrm{~s})$ & $2893(\mathrm{~s})$ & $2893(\mathrm{~m})$ & / & / & $\begin{array}{l}\text { Lv et al. (2015); } \\
\text { Owi et al. (2016) }\end{array}$ \\
\hline 1750 & $\begin{array}{l}\mathrm{C}=\mathrm{O} \text { ketone and } \\
\text { aldehyde (hemicellulose) }\end{array}$ & $1737(\mathrm{~m})$ & / & / & / & l & / & $\begin{array}{l}\text { Shanmugarajah et al. } \\
\text { (2015); Nurul et al. } \\
\text { (2017) }\end{array}$ \\
\hline 1640 & $\begin{array}{l}\mathrm{C}=\mathrm{C} \text { and } \mathrm{C}=\mathrm{O} \\
\text { aromatic lignin ring }\end{array}$ & / & $1638(\mathrm{~m})$ & $1634(\mathrm{~m})$ & $1614(\mathrm{~m})$ & l & & $\begin{array}{l}\text { Lv et al. (2015); } \\
\text { Shanmugarajah et al. }\end{array}$ \\
\hline 1424 & $\begin{array}{l}\equiv \mathrm{C}-\mathrm{H} \text { bending, } \\
=\mathrm{C}-\mathrm{H}_{2} \text { scissoring }\end{array}$ & $1419(w)$ & $1426(w)$ & $1424(w)$ & / & & & $\begin{array}{l}\text { Lv et al. (2015); } \\
\text { Zaini et al. (2013) }\end{array}$ \\
\hline 1400 & $\begin{array}{l}-\mathrm{CH}_{2},-\mathrm{CH}_{3}, \\
\mathrm{CH} \text { bending }\end{array}$ & $1373(w)$ & $1363(w)$ & $1364(w)$ & 1 & & $96(s)$ & $\begin{array}{l}\text { Lv et al. (2015); } \\
\text { Zaini et al. (2013) }\end{array}$ \\
\hline 1315 & $\begin{array}{l}\mathrm{CH}_{2} \text { wagging } \\
\text { in cellulose }\end{array}$ & & $1315(w)$ & $1315(w)$ & & & / & Lv et al. (2015) \\
\hline 1214 & $\begin{array}{l}\text { Phenolic and ester } \\
\text { C-O stretching }\end{array}$ & $1240(\mathrm{~m})$ & $1202(w)$ & 1200 & 1 & & / & $\begin{array}{l}\text { Kong et al. (2019); } \\
\text { Nurul et al. (2017); } \\
\text { Shanmugarajah et al. } \\
\text { (2015) }\end{array}$ \\
\hline 1160 & $\begin{array}{l}\text { Asymmetric vibration of } \\
\text { C-O-C }\end{array}$ & $1158(w)$ & $1160(\mathrm{~m})$ & $1158(\mathrm{~m})$ & $1156(w)$ & / & / & Huang et al. (2020) \\
\hline 1030 & $\begin{array}{l}\text { Tertiary alcohol } \\
\text { C-O stretch }\end{array}$ & $1031(\mathrm{~s})$ & $30(s)$ & $1025(\mathrm{~s})$ & $1025(\mathrm{~s})$ & $1059(\mathrm{~s})$ & / & $\begin{array}{l}\text { Lv et al. (2015); } \\
\text { Shanmugarajah et al. } \\
\text { (2015) }\end{array}$ \\
\hline 875 & Aromatic $\mathrm{C}-\mathrm{H}$ bending & & $897(\mathrm{~m})$ & $895(\mathrm{~m})$ & & $876(\mathrm{~s})$ & 872(s) & Kong et al. (2019) \\
\hline 799 & $\begin{array}{l}\text { Aromatic } \mathrm{CH} \\
\text { out-of-plane }\end{array}$ & 1 & & $713(w)$ & $767(w)$ & $713(\mathrm{~m})$ & $712(\mathrm{~m})$ & $\begin{array}{l}\text { Lv et al. (2015); } \\
\text { Keiluweit et al. (2010) }\end{array}$ \\
\hline 670 & C-C stretching & $663(\mathrm{~m})$ & $664(\mathrm{~m})$ & $667(\mathrm{~m})$ & $670(\mathrm{~m})$ & / & / & Owi et al. (2016) \\
\hline
\end{tabular}

Note: s-strong; m-moderate; w-weak; / means no visible peak.

FTIR - Fourier-transform infrared spectroscopy.
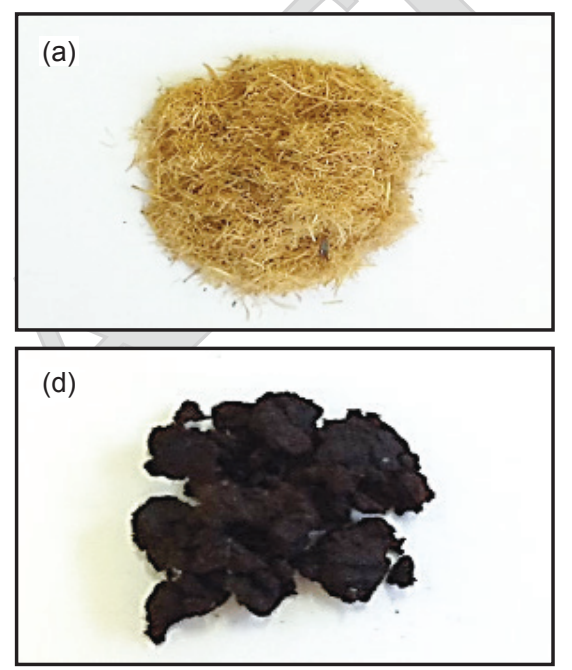

(b)

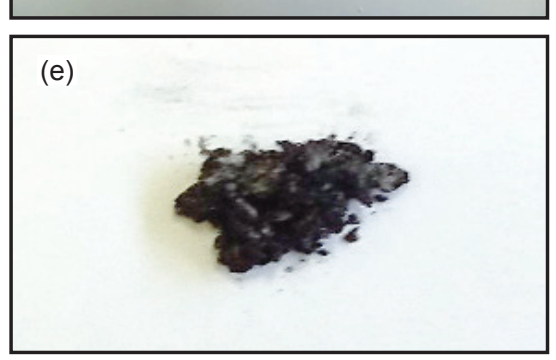

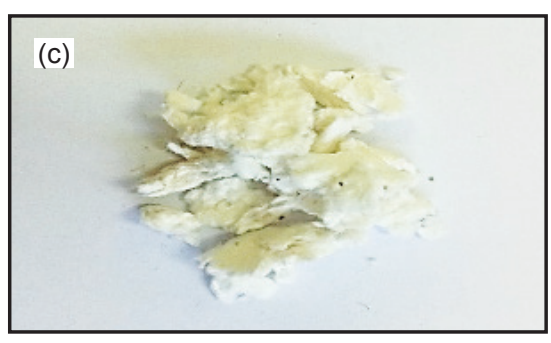

(f)

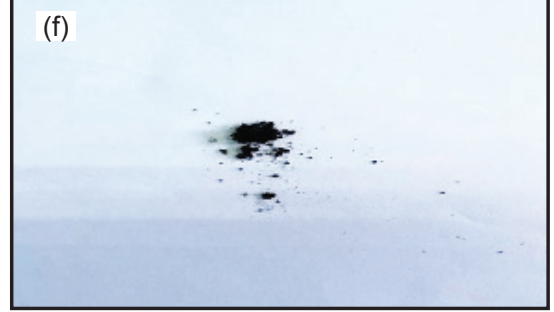

Figure 2. The physical image of (a) raw empty fruit bunch fibre in brown colour, (b) commercial cellulose as a fine white powder, (c) empty fruit bunch cellulose in whitish colour with rough texture; empty fruit bunch cellulose-derived biochar produced at (d) $250^{\circ} \mathrm{C},(e) 400^{\circ} \mathrm{C}$, and (f) $750^{\circ} \mathrm{C}-$ all of which had turned from whitish into blackish due to carbonisation process. 

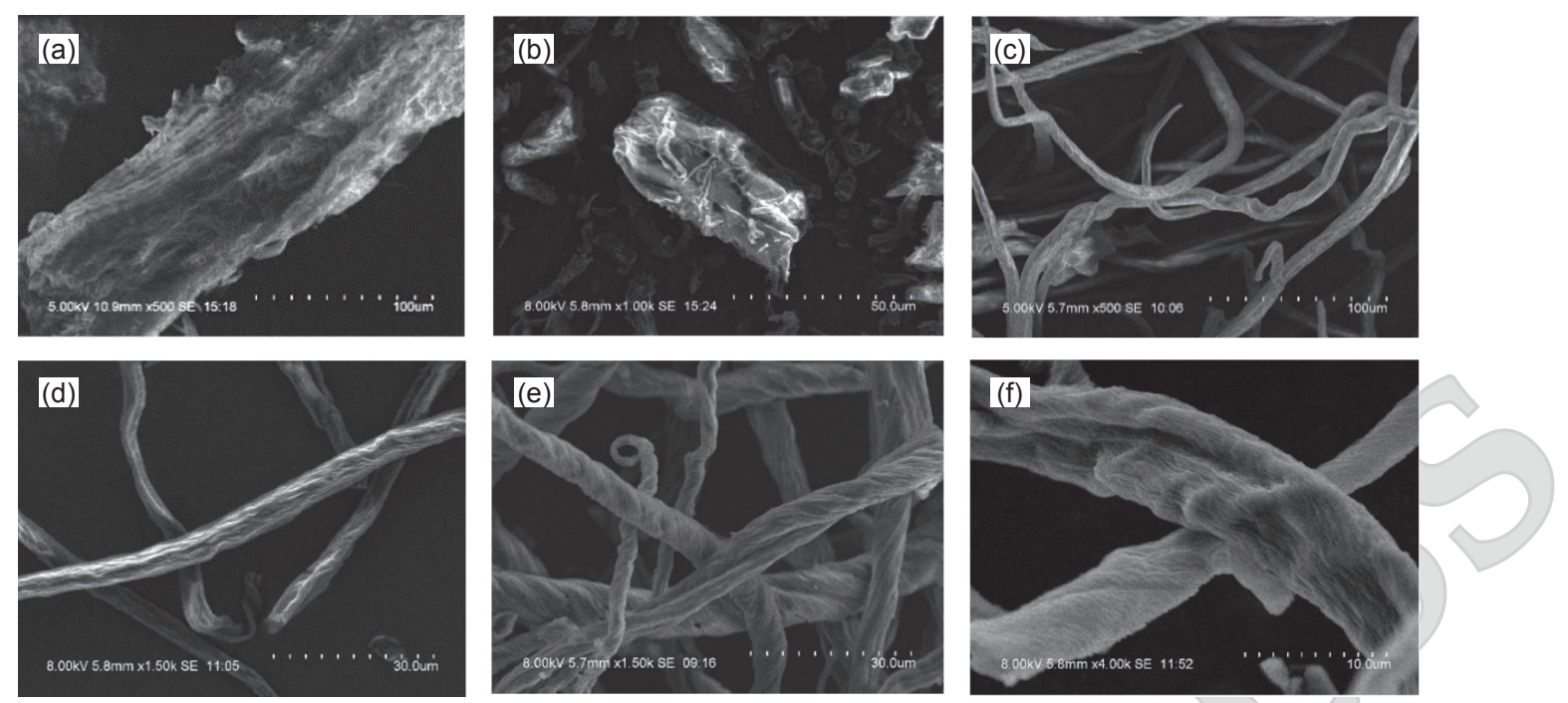

Figure 3. The scanning electron microscope (SEM) micrograph of (a) compact fibrillar packing surface of raw empty fruit bunch fibre; (b) an isolated fibril fibre fragments of commercial cellulose (c) a rod-shaped and individualise fibrous structure of empty fruit bunch cellulose; empty fruit bunch cellulosederived biochar produced at (d) $250^{\circ} \mathrm{C}$ with rough surface structure (e) $400^{\circ} \mathrm{C}$ with uneven surface, and (f) $750^{\circ} \mathrm{C}$ with crack outer surface owing to higher temperature intolerance.

\section{Proximate and Ultimate Analyses}

The properties of raw EFB fibre, commercial cellulose, EFBC and EFBC-derived biochar are summarised in Table 2. It can be observed that raw EFB fibre contains large percentage of VM (72.46 wt $\%)$, followed by fixed carbon (16.71 wt $\%)$, moisture $(8.03 \mathrm{wt} \%)$ and ash $(2.80 \mathrm{wt} \%)$, respectively. Meanwhile, the extracted cellulose, i.e. EFBC comprises of slightly higher VM content than the feedstock by $1.35 \%$ but lower fixed carbon (15.42 wt \%) and moisture content $(7.89 \mathrm{wt} \%)$ and the properties of EFBC were comparable with the commercial cellulose. In this study, the moisture content of the biochar was reduced from the feedstock through losses of water as steam due to the elevated temperatures employed. However, the moisture levels in the generated biochars increased as the temperature increased, i.e. $7.14 \mathrm{wt} \%\left(250^{\circ} \mathrm{C}\right)$, $15.59 \mathrm{wt} \%\left(400^{\circ} \mathrm{C}\right)$ and $17.75 \mathrm{wt} \%\left(750^{\circ} \mathrm{C}\right)$, due to the hydroscopic effect exerted by their higher surface areas (Askeland et al., 2019). Meanwhile, opposite trend was observed for $\mathrm{VM}$; the values decreased from $38.68 \mathrm{wt} \%\left(250^{\circ} \mathrm{C}\right)$ to $8.90 \mathrm{wt} \% \quad\left(750^{\circ} \mathrm{C}\right)$ which were consistent with other studies (Tag et al., 2016; Zhao et al., 2017) due to losses through outgassing. Furthermore, high temperature might have resulted in the dehydration of hydroxyl groups and thermal degradation of cellulose. The EFBC-derived biochars have lower percentage of VM as compared to raw EFB fibre because VM was released during the pyrolysis process. This study revealed that the percentages of fixed carbons in biochars (50.85-63.69 wt\%) were higher than those of the raw EFB fibre and EFBC. Fixed carbon was found to be higher in biochar produced at $750^{\circ} \mathrm{C}$.
Generally, higher values of fixed carbon would be indicative of a longer residence time of biochar in soil. These findings were in agreement with other studies by Shariff et al. (2014) and Domingues et al. (2017). Meanwhile, the ash fractions increased at higher temperature: from $0.74 \mathrm{wt} \%$ to 5.40 $\mathrm{wt} \%$ and this was expected because an increased devolatilisation during pyrolysis could reduce the oxygen content of biochar and thus, the ash content increased (Domingues et al., 2017). According to Tsai et al. (2012), increase in ash content in the biochar is due to the progressive concentration of minerals and destruction of lignocellulosic matters.

The ultimate analysis revealed that pyrolysis temperature affected the elemental compositions of the generated biochars (Table 2). The carbon content of EFBC (38.8 wt\%) increased with increasing temperature and reached $65.26 \mathrm{wt} \%$ at temperature of $400^{\circ} \mathrm{C}$ but slightly decreased $(42.27 \mathrm{wt} \%)$ with further increase of temperature until $750^{\circ} \mathrm{C}$. The decline was attributed to the reduction rate of carbonisation. Meanwhile, hydrogen $\left(\mathrm{H}_{2}\right)$ content decreased at higher pyrolysis temperature as methane $\left(\mathrm{CH}_{4}\right)$ and hydrogen formed and released during the pyrolysis process. This phenomenon is indicative of disappearance of some functional groups such as hydroxyl $(\mathrm{OH})$ and carbonyl $(\mathrm{COOH})$ through volatilisation (Bridgeman et al., 2008; Uemura et al., 2011b). The carbon and nitrogen contents in the EFBC-derived biochar increased while the oxygen and hydrogen contents decreased with increasing temperature compared to the initial feedstock (empty fruit bunch cellulose). However, this trend was invalid at pyrolysis temperature of $750^{\circ} \mathrm{C}$ as the carbon and oxygen contents fluctuated. The carbon content of biochar is an 
TABLE 2. ULTIMATE AND PROXIMATE ANALYSIS OF RAW EMPTY FRUIT BUNCH (EFB) FIBRE, COMMERCIAL CELLULOSE, EFB CELLULOSE (EFBC) AND EFBC-DERIVED BIOCHAR

\begin{tabular}{|c|c|c|c|c|c|c|c|c|}
\hline $\begin{array}{l}\text { Parameter } \\
\text { (wt. } \% \text { d.b.) }\end{array}$ & $\mathrm{C}$ & $\mathbf{H}$ & $\mathbf{N}$ & $\mathrm{O}^{\mathrm{a}}$ & $\begin{array}{l}\text { Moisture } \\
\text { content }\end{array}$ & $\begin{array}{c}\text { Volatile } \\
\text { matter }\end{array}$ & $\begin{array}{c}\text { Fixed } \\
\text { carbon }\end{array}$ & $\begin{array}{c}\text { Ash } \\
\text { content }\end{array}$ \\
\hline Raw EFB fibre & 44.08 & 7.54 & 0.15 & 48.21 & 8.03 & 72.46 & 16.71 & 2.80 \\
\hline Commercial cellulose & 41.02 & 7.37 & $<0.01$ & 51.58 & 6.40 & 83.49 & 10.17 & $<0.01$ \\
\hline EFBC & 38.80 & 6.96 & 0.18 & 54.06 & 7.89 & 73.81 & 15.42 & $<0.01$ \\
\hline EFBC-derived biochar $\left(250^{\circ} \mathrm{C}\right)$ & 57.98 & 2.38 & $<0.01$ & 39.64 & 7.14 & 38.68 & 50.85 & 0.74 \\
\hline EFBC-derived biochar $\left(400^{\circ} \mathrm{C}\right)$ & 65.26 & $<0.01$ & 0.41 & 34.33 & 15.59 & 20.32 & 58.29 & 0.89 \\
\hline EFBC-derived biochar $\left(750^{\circ} \mathrm{C}\right)$ & 42.27 & $<0.01$ & $<0.01$ & 57.73 & 17.75 & 8.90 & 63.69 & 5.40 \\
\hline
\end{tabular}

Note: ${ }^{a}$ Estimated by difference: $\% \mathrm{O}=100 \%$ - $[\%$ carbon $(\mathrm{C})+\%$ hydrogen $(\mathrm{H})+\%$ nitrogen $(\mathrm{N})]$.

important indicator to identify its potential carbon sequestration during soil application (Duku et al., 2011; Galinato et al., 2011). According to Imam and Capareda (2012), the fluctuation might be caused by the breaking of weak bonding in the biochar structure although high carbonaceous materials are produced with increasing temperature.

Figure 4 shows that the EFBC-derived biochar production decreased markedly from $32.51 \% \pm 0.48$ to $9.02 \% \pm 0.13$ as the pyrolysis temperature escalated from $250^{\circ} \mathrm{C}-400^{\circ} \mathrm{C}$. At this point, most of the lignocellulosic materials were more likely to decompose as reported by Intani et al. (2016). Nevertheless, the production of EFBC-derived biochar merely decreased further by $5 \%$ at $750^{\circ} \mathrm{C}$, which indicated extensive decomposition of most of the volatile fractions (Lua et al., 2004). At higher temperatures, organic compounds with higher molecular weight in the biomass could devolatilise into lower molecular weight compounds along with some light gases as well (Thangalazhy et al., 2010). Dehydration and elimination would proceed faster at higher temperatures, which leads to a decreased biochar yield. Demirbas (2004) reported that biochar production relies on the adverse reaction of cellulose and biochars polymerisation process. The biochar product yield is an important factor for realising economic benefit in biomass waste reutilisation. From the finding, higher pyrolysis temperatures caused greater losses of VM, oxygen, hydrogen as well as biochar yield due to depolymerisation of lignocelluloses and carbonisation to a more recalcitrant form through decarboxylation, dehydration, condensation and aromatisation reactions (Das and Sarmah, 2015; Heitkotter and Marschner, 2015). Future study will focus on pyrolytic mechanism and the associated kinetics to understand wholly the biomass-tobiochar conversion process.

\section{CONCLUSION}

The present work concludes that cellulose was successfully extracted from the raw EFB fibre and the extracted cellulose exhibited similar properties as the commercially available cellulose. The findings highlighted that different pyrolysis temperature had

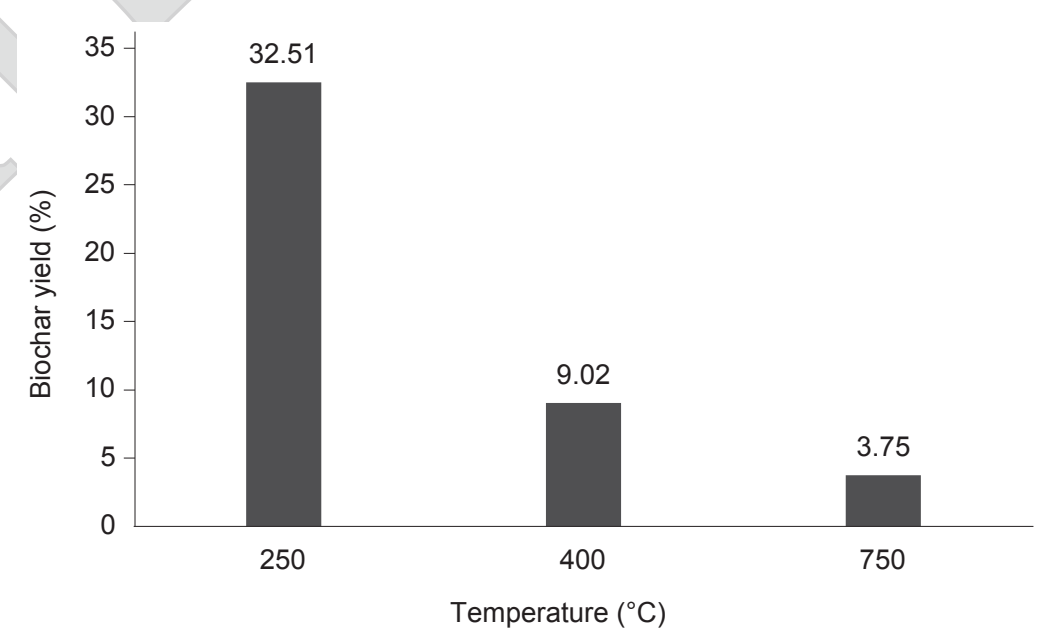

Figure 4. Biochar yield at different pyrolysis temperatures. The highest yield, $32.51 \%$ was achieved at $250^{\circ} \mathrm{C}$ and significantly decreased as the temperature increased. The carbonisation rate of biochar was enhanced with increasing temperature due to the thermal degradation of organic and inorganic materials that were released in the form of volatile components. 
greatly influenced the physiochemical properties of the EFBC-derived biochars. The morphology and structure of the produced biochars were distinctively different in shape and form with increasing temperature. The biochar yield and total elemental content (oxygen, hydrogen and nitrogen) reduced while the carbon and ash content increased with increasing temperature. The highest achievable biochar yield was $32.51 \%$ at $250^{\circ} \mathrm{C}$. The FTIR spectra revealed some variations and similarities in functional groups between the feedstocks and the EFBC-derived biochars. The biochars produced at lower temperature $\left(250^{\circ} \mathrm{C}\right)$ exhibited characteristics favourable as a soil enhancer in improving soil fertility and quality such as high VM (38.68 wt \%) and carbon (57.98 wt\%) contents. Furthermore, other potential biochar applications can be considered including as an energy source (biofuel) and pollution remediation. Findings from this study provide insights into relationships between pyrolysis conditions, biochar properties and biochar processing which are crucial in optimising biochar production for soil application.

\section{ACKNOWLEDGEMENT}

The authors would like to thank the Director-General of MPOB for the permission to publish this article.

\section{REFERENCES}

Askeland, M; Clarke, B and Paz-Ferreiro, J (2019). Comparative characterization of biochars produced at three selected pyrolysis temperatures from common woody and herbaceous waste streams. PeerJ, 7: 6784.

Aziz, N; Mohd, N; Mohd, A; Manaf, S and Hamzah, F (2015). Suitability of biochar produced from biomass waste as soil amendment. Procedia - Social and Behavioral Sciences, 195: 2457-2465.

Bridgeman, T G; Jones, J M; Shield, I and Williams, P T (2008). Torrefaction of reed canary grass, wheat straw and willow to enhance solid fuel qualities and combustion properties. Fuel, 87: 844-856.

Cantrell, K B; Hunt, P G and Uchimiya, M (2012). Impact of pyrolysis temperature and manure source on physiochemical characteristics of biochar. Bioresource Technology, 107: 419-428.

Chan, K Y; Zwieten, L V; Meszaros, I; Downie, A and Joseph, S (2008). Using poultry litter biochars as soil amendments. Australian J. Soil Research, 46: 437-444.
Claoston, N; Samsuri, A W; Ahmad, M H and Mohd, A M S (2014). Effects of pyrolysis temperature on the pysiochemical properties of empty fruit bunch and rice husk biochars. Waste Management and Research, 32(4): 331-339.

Das, O and Sarmah, AK (2015). The love-hate relationship of pyrolysis biochar and water: A perspective. Science of the Total Environment, 512: 682-685.

Demirbas, A (2004). Effects of temperature and particle size on biochar yield from pyrolysis of agricultural waste. J. Analytical and Applied Pyrolysis, 72: 243-248.

Domene, X; Enders, A; Hanley, $\mathrm{K}$ and Lehmann, J (2015). Ecotoxicological characterization of biochars: Role of feedstock and pyrolysis temperature. Science of the Total Environment, 512-513: 552-561.

Domingues, R R; Trugilho, P F; Silva, C A; de Melo, I C N A; Melo, L C A; Magriotis, Z M and Sa'nchezMonedero, M A (2017). Properties of biochar derived from wood and high-nutrient biomasses with the aim of agronomic and environmental benefits. PLoS ONE, 12: $\mathrm{e} 0176884$.

Draman, S F S; Daik, R; Latif, F A and El-Sheikh, S M (2013). Characterization and thermal decomposition kinetics of kapok (Ceiba pentandra L.)-based cellulose. BioResources, 9(1): 8-23.

Duku, M H; Gu, S and Hagan, E (2011). Biochar production potential in Ghana - A review. Renewable Sustainable Energy Reviews, 15(8): 3539-3551.

Galinato, S P; Yoder, J K and Granatstein, D (2011). The economic value of biochar in crop production and carbon sequestration. Energy Policy, 39(10): 6344-6350.

Heinze, T; El Seoud, O A and Koschella, A (2018). Cellulose Derivatives; Springer Series on Polymer and Composite Materials. Springer International Publishing, Cham, Switzerland.

Heitkotter, J and Marschner, B (2015). Interactive effects of biochar ageing in soils related to feedstock, pyrolysis temperature and historic charcoal production. Geoderma, 245-246: 56-64.

Huang, S; Tao, R; Ismail, A and Wang, Y (2020). Cellulose nanocrystals derived from textile waste through acid hydrolysis and oxidation as reinforcing agent of soy protein film. Polymers, 12: 958.

Idris, J; Shirai, Y; Ando, Y; Amiruddin, A; Ali, M; Othman, M; Ibrahim, I and Hassan, M A (2014). Production of biochar with high mineral content 
from oil palm biomass. The Malaysian J. Analytical Sciences, 18: 700-704.

Imam, T and Capareda, S (2012). Characterization of bio-oil, syn-gas and biochar from switchgrass pyrolysis at various temperatures. J. Analytical and Applied Pyrolysis, 93: 170-177.

Intani, K; Latif, S; Kabir, A K M R and Muller, J (2016). Effect of self-purging pyrolysis on yield of biochar from maize cobs, husks and leaves. Bioresource Technology, 218: 541-551.

Keiluweit, M; Nico, P S; Johnson, M G and Kleber, M (2010). Dynamic molecular structure of plant biomass-derived black carbon (biochar). Environmental Science and Technology, 44: 1247-1253.

Khalil, H P S A; Ismail, H; Rozman, H D and Ahmad, M N (2001). The effect of acetylation on interfacial shear strength between plant fibres and various metrices. European Polymer J., 37(5): 1037-1045.

Kong, S H; Loh, S K; Bachmann, R T; Haryati, Z and Cheong, K Y (2019). Palm kernel shell biochar production, characteristrics and carbon sequestration potential. J. Oil Palm Res. Vol. 31(3): 508-520.

Kushairi, A; Meilina, O A; Balu, N; Elina, H; Zanal, B M N I; Razmah, G; Vijaya, S; Shamala, S and Parveez, G K A (2019). Oil palm economic performance in Malaysia and R\&D progress in 2018. J. Oil Palm Res. Vol. 31(2): 165-194.

Lahijani, P and Zainal, Z A (2011). Gasification of palm empty fruit bunch in a bubbling fluidised bed: A performance and agglomeration study. Bioresource Technology, 102: 2068-2076.

Lani, N S; Ngadi, N; Johari, A and Jusoh, M (2014). Isolation, characterization, and application of nanocellulose from oil palm empty fruit bunch fiber as nanocomposites. J. Nanomaterials, 3: 1-9.

Lorenz, K (2007). Strengthening the soil organic carbon pool by increasing contributions from recalcitrant aliphatic bio (macro) molecules. Geoderma, 142: 1-10.

Lua, A C; Yang, T and Guo, J (2004). Effects of pyrolysis conditions on the properties of activated carbons prepared from pistachio-nut shells. J. Analytical and Applied Pyrolysis, 72: 279-287.

Lv, Pin; Almeida, G and Perre, P (2015). TGA-FTIR of torrecfaction of lignocellulosic components (cellulose, xylan, lignin) in isothermal conditions over a wide range of time durations. Bioresources, 10(3): 4239-4251.
Mayoral, M C; Izquierdo, M T; Andre, J M and Rubio, B (2001). Different approaches to proximate analysis by thermogravimetry analysis. Thermochimica Acta, 370: 91-97.

Nazir, M S; Wahjoedi, B A; Yussof, A W and Abdullah, M A (2013). Eco-friendly extraction and characterization of cellulose from oil palm empty fruit bunches. Bioresources, 8(2): 2161-2172.

Novianti, S; Biddinika, M K; Prawisudha, P and Yoshikawa, K (2014). Upgrading of palm oil empty fruit bunch employing hydrothermal treatment in lab-scale and pilot scale. Procedia Environmental Sciences, 20: 46-54.

Nurul, S R; Shuhaida, H; Jamaliah, J and Rizafizah, O (2017). Chemical and physical characterization of oil palm empty fruit bunch. Malaysian J. Analytical Sciences, 21(1): 188-196.

Owi, W T; Lin, O H; Sam, S T; Chin, C H; Zakaria, S, Mohaiyiddin, M S; Villagracia, A R; Santos, G N and Akil, H M (2016). Comparative study of microcelluloses isolated from two different biomasses with commercial cellulose. Bioresources, 11(2): 3453-3465.

Shafie, S T; Mohd, S M A; Hang, L L; Rahman, M M and Wan, A K G W A (2012). Effect of pyrolysis temperature on the biochar nutrient and water retention capacity. J. Purity, Utility Reaction and Environment, 1(6): 323-337.

Shanmugarajah, B; Kiew, P L; Chew, I M; Choong, T $S$ and Tan, K W (2015). Isolation of nanocrystalline cellulose (NCC) from palm oil empty fruit bunch (EFB): Preliminary result on FTIR and DLS analysis. Chemical Engineering Transactions, 45: 1705-1710.

Shariff, A; Aziz, N S M and Abdullah, N (2014). Slow pyrolysis of oil palm empty fruit bunches for biochar production and characterization. J. Physical Science, 25(2): 97-112.

Sohi, S; Lopez, C E; Krul, E and Boll, R (2009). Biochar, climate change and soil: A review to guide future research. CSIRO Land and Water Science Report Series, 2008.

Suriya, P; Pongsathorn, D; Wanna, C; Yusuf, C and Poonsuk, P (2017). Cellulose and hemicellulose recovery from oil palm empty fruit bunch (EFB) fibers and production of sugars from the fibers. Carbohydrate Polymers, 155: 491-497.

Tag, A T; Duman, G; Ucar, S and Yanik, J (2016). Effects of feedstock type and pyrolysis temperature on potential applications of biochar. J. Analytical and Applied Pyrolysis, 120: 200-206. 
Thangalazhy, G S; Adhikari, S; Ravindran, H; Gupta, R B; Fasina, O; Tu, M and Fernando, S D (2010). Physiochemical properties of bio-oil produced at various temperatures from pine wood using an auger reactor. Bioresource Technology, 101: 8389-8395.

Tsai, W T; Liu, S C; Chen, H R; Chang, Y M and Tsai, Y L (2012). Textural and chemical properties of swine-manure-derived biochar pertinent to its potential use as a soil amendment. Chemosphere, 89: 198-203.

Uemura, Y; Omar, W N; Othman, N A; Yusup, $S$ and Tsuisui, T (2011a). Effect of atmosphere on torrefaction of oil palm wastes. World Renewable Energy Congress Sweden, 69: 516-523.
Uemura, Y; Omar, W N; Tsutsui, T and Yusup, S (2011b). Torrefaction of oil palm wastes. Fuel, 90: 2585-2591.

Wan, R W D; Rohaizu, R and Ghazali, A (2011). Synthesis and characterization of cellulose phosphate from oil palm empty fruit bunches. Carbohydrate Polymers, 84: 262-267.

Zaini, L H; Jonoobi, M; Tahir, P M and Karimi, S (2013). Isolation and characterization of cellulose whiskers from kenaf (Hibiscus cannabinus L.) bast fibers. Cellulose, 17(5): 977-985.

Zhao, S X; Na, T and Wang, X D (2017). Effect of temperature on the structural and physicochemical properties of biochar with apple tree branches as feedstock material. Energies, 10(9): 1293. 